\title{
Religion and Resilience of Parents with a Child with Autism Spectrum Disorders
}

\author{
Paschalis Kavaliotis ${ }^{1}$ \\ ${ }^{1}$ Department of Special Education and Psychology, Faculty of Primary Education, National and Kapodistrian \\ University of Athens, Greece \\ Correspondence: Paschalis Kavaliotis, Department of Special Education and Psychology, Faculty of Primary \\ Education, National and Kapodistrian University of Athens, Greece. E-mail: apk1@otenet.gr
}

Received: February 1, 2017

Accepted: February 9, $2017 \quad$ Online Published: February 16, 2017

doi:10.5539/ijps.v9n2p16

URL: http://doi.org/10.5539/ijps.v9n2p16

\begin{abstract}
The resilience of parents with children with autism is a key concept in the confrontation of the autism challenges which demand parents who are mentally healthy and who will be in a position to satisfy the special needs of their autistic children, however, without sinking into loneliness and isolation which affect the less resistant families and upset their inner balance. The parents resort to various sources for the strengthening of resilience, it is the power of God both as a cause of the origin of autism and as the unique or one of the possible ways of resolving the problem. This survey investigated the views on divine will as to the origin and confrontation of autism in families of Christians and Muslims and it attempted to highlight the possible differences in the culture of these groups that are different in terms of culture and religion. The parents of 312 autistic children in Greece, all of them couples, namely 624 men and women, constituted the population sample. The quantitative survey results showed that the Greek Christians satisfy more efficiently their child's needs, perhaps because they attribute lesser importance to the factor of the Divine compared to the parents of other religions. The weaker connection between the origin and management of the disease and the Divine will allows them to invest in scientific help for addressing a problem which in fact they perceive in more positive social terms than the Muslims do.
\end{abstract}

Keywords: resilience, autism, autistic child, religion, Christians, Muslims

\section{Introduction}

In this paper the term "resilience" means an acquired and not an innate personal characteristic, which for the most part depends on the supporting relations of the parents, the peers and others, aiming at the individual's strengthening in order to manifest elements of positive adjustment in spite of the existence of serious threats, difficulties, wounds and pressures. According to Hamilton (2014) certain families respond successfully to the autism challenge, whereas other families do not cope with it equally well, with an important effect on various sectors of family life. Resilience is understood as the positive adaptation to the context of a big change and it has been the center of a great deal of attention in latest years, due to the increasing awareness of the various factors that affect it within the family.

The exploration of the effect of the faith in God, as a factor reinforcing the parents' resilience appeared as an interesting parameter during the search for the theoretic basis of this paper, so it was initially concluded that in latest years there has been an increasing interest in the justification for and in the management of autism in the so called non-western world. And this is not a secondary parameter or a consideration of a reduced interest, because its criticality is interconnected to the importance of concluding whether certain social structures, which concern also the relation to the Divine, strengthen the resilience on different percentages which are directly related to geographical and consequently to cultural parameters. For instance, the following question may be posed: Is the faith in God a strengthening parameter equally significant to the western and non-western world, or does it receive "increased preference" in environments where the scientific approach is contrasted with the faith in and devotion to God's commands, both as to the origin and treatment of the autism spectrum disorders? Indeed, certain studies have been carried out, directly linked to these crucial issues. Nonetheless, because these studies are too limited in number, vital conclusions cannot be drawn because the behavioral tendencies of the persons' concerned are not adequately described. 
From the relatively recent studies, the one by Bashir, Khursid and Qadri (2014) set the faith in God as a parameter, both in relation to the parents' faith concerning the origin of autism and in relation to its management strategies. The results come from parents of five children only, in fact, from an Indian province, therefore, it is not easy to be presumed that there is a possibility for their generalization in the western world in particular. However, it is necessary to mention these results due to the rarity of the reference to the faith parameter.

The variables that showed the parents' views on the origin of autism were the following, together with the percentages they received: divine wish $=3$ out of 5 parents, $60 \%$ percentage; older sins of the parents $=0$ out of 5 parents, $0 \%$ percentage; lack of medical facilities $=1$ out of 5 parents, $20 \%$ percentage, lack of awareness $=1$ out of 5 parents, $20 \%$ percentage. Most parents considered the problem as a gift from God, consequently they did not feel even the slightest sorrow for having this child in the family. As for the rest, the fact that due to various reasons, the child could not have access to hospital treatment, was assumed that it affects his condition, as well as the ignorance of the community about those children who suffer from any kind of disabilities, therefore, the child's condition in these cases is overlooked.

In management strategies the family support and divine power tied with 2 parents in each case, therefore, $40 \%$. The economic safety was preferred only by one parent, consequently, it received $20 \%$. None mentioned another strategy. These numbers mean that the family support and the faith in God contribute equally to the support of the parents and help them equally in their life course so as to cope with the daily routine. Only one parent preferred to choose the economic safety as a way to help the child, as he/she considered that in this way he/she can cover the current expenses.

It would be interesting to examine the demographic data of the parents who participated in the survey, however, Bashir, Khursid and Qadri mention only that they came from urban areas in the Srinagar district. They were chosen via the method of random systematic sampling.

A reference to the religious support parameter is found also in the Yarock Rutstein research (2014), nevertheless, its data come from an older paper by other researchers who in 1997 explored the support provided by official services to parents with children with autism, Down Syndrome, and with neurotypical children. But the study results showed that, regardless of the official support the parents receive from organizations, the lack of informal social support may lead to a withdrawal from the wider community due to the stigmatization that is linked to the negative characteristics of child disability. It was concluded that the mothers of the children with autism were those ones with the bigger difficulties in acquiring forms of informal communication based on the community, such as the support from religious groups and parent support groups. The specific 1997 reference which Yarock Rutstein repeats shows that apart from the individual faith in God, the religious groups undertake also the psychological support for the parents.

Brown (2014) refers to the religious support, too, however, she measures it as one of the less available forms of support, together with the parent groups, the social groups and associations and associates. Possibly, the parents do not have the time to seek help in many outer domestic organizations.

From the surveys studied by the author of this paper one that refers to the notion of the Divine and to its influence on the believers' life, being one of the most recent one that came to public attention, is that by Gona et al. (2016) from Kenya. It is characteristic that the coping strategies applied by the parents in this African country focus on practical cares, such as the nutrition management and the care provided by the competent institution, as well as on emotional aspects that concern the appeal to God, with the faith in supernatural powers, prayers and a "request" for spiritual healing. Many parents believe that autism is due to a predetermined God's plan, hence, they cultivate expectations also for his intervention in resolving the problem. That is to say, the confrontation strategies aim at the child's physical health and the parents' psychological wellbeing through faith and praying.

From all these, it is concluded that from the relatively recent researches, only one sets the faith in God as a parameter and that is the survey by Bashir, Khursid and Qardi (2014), which not only does it explore faith as a parameter for enhancing the resilience, but also it explores the belief that there is a relation between the divine will and the origin of autism. It was noted that the results' reliability may be questioned as to their objectivity in the said research due to the participants' possible religiosity who, after all, were few in number. As for the research conducted by Gona et al. (2016) from Kenya, it demonstrated that apart from the scientific confrontation strategies, such as the nutrition care and the care provided by the competent institution, the emotional world and the feeling of devoutness of the parents with autistic children attribute autism to a predetermined God's plan who is thus responsible for resolving the problem. More generally, a research gap emerges and this is what the present paper attempted to fill in, "filling in the empty space" of the researchers" interest in faith and religious groups as a factor for reinforcing resilience. 
The mention to the aforementioned researches and studies shaped a short theoretical context for the cultural and religious confrontation of the autism syndrome, which maybe could be important to Greece, too, where it would perhaps be concluded that minority parents, such as Muslims, cope with the problem in a different way than the majority Greek Orthodox parents do. It is understood that the wider environment affects the views and maybe the more extreme ones of them from the non-western world are not confirmed with the same sharpness and keenness in Greece, but this remained to be found through the quantitative research process, as described in the text that follows.

\section{Method}

\subsection{Purpose}

This article is part of a wider research that aimed in exploring the way in which the family resilience of parents with a child with autism spectrum disorders interacts with the social context among which the family is placed, as well as with the stress the parents experience during the upbringing of a child with autism spectrum disorders. It is important to investigate how the resilience is affected when the social support that the family receives is low and the true stress high, with variables, apart from the level of social support that the parents receive and the stress they suffer from, certain demographic characteristics of the parents and of the child, too, such as age, sex and the diagnosis of the syndrome the child suffers from. In this article, the results of the investigation of the relation between the parents' family resilience and their religion are shown, in order to indicate whether the differences that are also found between the said western and non-western world are also reflected in Greece, among the minorities and the majorities of the population.

\subsection{Participants}

Table 1. Demographic and other characteristics of the participants in the survey

\begin{tabular}{|c|c|c|}
\hline & $\mathbf{n}$ & $\%$ \\
\hline \multicolumn{3}{|l|}{ Sex } \\
\hline Men & 312 & 50,0 \\
\hline Women & 312 & 50,0 \\
\hline \multicolumn{3}{|l|}{ Nationality } \\
\hline Greek & 609 & 97,6 \\
\hline Other & 15 & 2,4 \\
\hline \multicolumn{3}{|l|}{ Religion } \\
\hline Christians & 586 & 93,9 \\
\hline Muslims & 38 & 6,1 \\
\hline \multicolumn{3}{|l|}{ Prefecture of } \\
\hline Kavala & 52 & 8,3 \\
\hline Rodopi & 80 & 12,8 \\
\hline Xanthi & 72 & 11,5 \\
\hline Cyclades & 74 & 11,9 \\
\hline Serres & 96 & 15,4 \\
\hline Drama & 120 & 19,2 \\
\hline Evros & 130 & 20,8 \\
\hline \multicolumn{3}{|l|}{ Education } \\
\hline Primary Education & 171 & 27,4 \\
\hline Secondary School Graduates & 80 & 12,8 \\
\hline Lyceum Graduates & 168 & 26,9 \\
\hline HEI /TEI Graduates & 205 & 32,9 \\
\hline Studies in Psychology or in Special Education & 0 & 0,0 \\
\hline \multicolumn{3}{|l|}{ Annual Family Income } \\
\hline Below $15.000 €$ & 266 & 42,6 \\
\hline $15.000 €-20.000 €$ & 272 & 43,6 \\
\hline
\end{tabular}




\begin{tabular}{lcc}
\hline Over $20.000 €$ & 86 & 13,8 \\
Family Status & & 0,0 \\
Single & 0 & 100,0 \\
Married & 624 & 0,0 \\
Widower/ Widow & 0 & 0,0 \\
Divorced & 0 & \\
Family Relation to the Child & & 50,0 \\
Biological Father & 312 & 50,0 \\
Biological Mother & 312 & 0,0 \\
Step-father & 0 & 0,0 \\
Step-mother & 0 & \\
\hline
\end{tabular}

As shown in Table 1, 624 parents of 312 children with autism spectrum disorders participated in the survey. The sample is uniformly distributed as to the parents' sex with $50.0 \%$ men and the same percentage of women. $97,6 \%$ of the sample, namely 609 parents, are Greeks, whereas $2,4 \%$, namely 15 participants, are of a different nationality. 586 of the participants are Christians, $93,9 \%$ of the sample, whereas the remaining $6,1 \%$, that is to say, 38 parents, are Muslims. As far as their place of residence in the Greek territory is concerned, 52 parents $(8,3 \%$ of the total number) reside in the prefecture of Kavala, 80 parents $(12 \%$ of the total number) reside in the prefecture of Rodopi, 72 participants $(11,5 \%$ of the sample) in the Xanthi prefecture, 74 parents $(11,9 \%$ of the sample) in the prefecture of Cyclades, 96 parents $(15,4 \%$ of the total number) in the prefecture of Serres, 120 parents $(19,2 \%$ of the total) in the prefecture of Drama and 130 parents $(20,8 \%$ of the sample) in the prefecture of Evros.

The total number of the respondents $(100,0 \%$ of the sample) are married and they are the biological parents of the child with autism spectrum disorders, $312(50,0 \%$ of the sample) are the biological mothers and $312(50,0 \%$ of the sample) the biological fathers.

The highest level of education for $27,4 \%$ of the participants (171 parents) is that of the primary education, $12,8 \%$ of the participants (80 parents) have received a low secondary education (gymnasium), 26,99\% (168 parents) have received a high secondary education (lyceum), whereas the rest of the participants, that is to say, $32,9 \%$ of the sample (205 parents) have received a post-secondary education, as they are graduates of Higher Educational Institutes (HEI) and Technological Educational Institutes (TEI).

Concerning the annual family income, $42,6 \%$ of the sample (266 parents) declared an amount below $15.000 €$, $43,6 \%$ of the total number (272 parents) between $15.000 €$ and $20.000 €$ and the remaining $13,8 \%$ (86 parents), an income over $20.000 €$.

The children's characteristics are summarized in Table 1 in this text.

Table 2. Sex of the children with autism spectrum disorders and Asperger syndrome

\begin{tabular}{lcc}
\hline & $\mathbf{n}$ & $\mathbf{\%}$ \\
\hline Sex & & \\
Boy & 253 & 81,1 \\
Girl & 59 & 18,9 \\
Diagnosis & & \\
Autism & 282 & 90,4 \\
Asperger & 30 & 9,6 \\
I don't know & 0 & 0 \\
\hline
\end{tabular}


Table 3. Characteristic age values of the children with autism spectrum disorders

\begin{tabular}{lcccc}
\hline & $\begin{array}{c}\text { Mean } \\
\text { Value* }\end{array}$ & $\begin{array}{c}\text { Standard } \\
\text { Deviation }\end{array}$ & Skewness & Kurtosis \\
\hline The Age of Children with Autism Spectrum Disorders & 12,45 & 5,33 & 1,184 & 1,937 \\
\hline
\end{tabular}

With regard to the child's sex, $81,1 \%$ of the respondents, namely 506 in number, are boys' parents and the remaining 118 parents $(18,9 \%$ of the sample) are girls' parents. The average age of the 312 children whose parents participated in the research is $M=12,45$ years with standard deviation $S D=5,3$ years. $90,4 \%$ of these children, that is to say, 282 in terms of numbers, have been diagnosed with autism, whereas the remaining 30 children, $9,6 \%$ of the total number, have been diagnosed with Asperger syndrome. The children's characteristics are summarized in Tables 2 and 3 in the present text.

\subsection{Note}

The demographic characteristics of the families with dysfunctional children are factors relating directly to the parents' stress levels (Houser \& Seligman, 1991; Keller \& Honig, 2004). For this reason the questionnaire that was distributed to the participants contained specific fields the completion of which would provide the necessary demographic information on each family, namely on the sex, nationality, religion, education level, annual family income, current family status, family relation to the autistic child, the child's age and sex, as well as his accurate diagnosis.

\subsection{Data Collection}

The supplying and collection of the questionnaires were realized by the writer from July 2015 to February 2016. The search for parents with children with autistic spectrum disorders was conducted based on the catalogues of the Center for Differential Diagnosis, Diagnosis and Support (KE.D.D.Y.) in the prefectures of the Greek territory, where an archive is kept on the children that receive a diagnosis. The parents were approached via mail sent to their residence address, to which the research questionnaire was attached, as well as an accompanying form that informed them in detail of the purpose and the aims of the research process. Special emphasis was put on the importance of confidentiality and anonymity of the information, namely that the data of the child and of the parents themselves would remain anonymous, whereas the information will be used exclusively for the needs and the purpose of the present research.

Though the accompanying form the parents were informed that they had to complete the entire questionnaire and the duration of its completion should not exceed 60 minutes. The participants were urged to contact the researcher on his mobile phone for the provision of instructions and clarifications about the correct completion of the questionnaire. Moreover, the importance of the completion by every parent separately was specifically pointed out to the participants, without there being an exchange of views among the couples, so that the achievement of the research's aims be possible.

The collection of the completed questionnaires was realized with their return to the researcher, by mail, from the families that had consented to an analysis of their answers. The return of the questionnaires to the researcher was defined to take place within 30 days after the date of their dispatching to these families.

\subsection{Data Analysis}

For the investigation of the relations that govern the Social Support, Family Resilience and Parental Stress of parents with children with Autism spectrum disorders, the following three data collection tools were used.

Social Support Index: The degree of the social support of parents who have a child with autism spectrum disorders was measured with the widely spread SSI tool (McCubbin, Patterson, \& Glynn, 1982) which assesses the family social support as a factor in family resilience (Fischer, Corcoran, \& Fischer, 2007). It contained 16 questions the answers to which were given in the 5-point Likert scale ( 0 up to 4$)$. In every questionnaire statement, the respondents can state the measure of their agreement or disagreement by choosing one of the following answers: "I strongly disagree", "I agree", "I am not sure", "I agree" and "I fully agree", which are ranked on a scale of 0 to 4 . In certain answers the scale was reversed so that a common conceptual content could be achieved. As to the answers' interpretation for the definition of the Social Support degree, the scores of the individual questions are summed, the highest scores indicating a highest Social Support degree. The span of the SSI scale was from 0 to 6 units. The SSI has a high internal validity index with a $=0,82$. The Social Support scale was used as an independent variable. 
Family Resilience Assessment Scale: The FRAS scale of Tucker Sixbey (2005) was used to measure Family Resilience, based on the theoretical standard of Walsh (2006) on family resilience. It contained 66 closed-type questions which, as in the SSI case, they were answered in the Likert scale, but in a 4-point one, with values varying from 1 to 4, corresponding to the choices: "I strongly disagree", "I disagree", "I agree" and "I fully agree". The scale was reversed in four of these questions, and again for the acquisition of a common conceptual content. There was also an open-ended question. From these questions 54 were assessed, which were grouped together and formed 6 subscales of family resilience, as Tucker Sixbey (2005) suggests. More specifically, the subscales are as follows: 1) Family Communication and Problem Solving: here, 27 questions of the data collection tool correspond to it. The result of the subscale is given with Cronbach's alpha coefficient 0,96, whereas the horizontal sum of the individual questions forms the subscale's final rating with a span from 27 to 108 units. 2) Utilizing Social and Economic Resources: It is formed by 8 questions. Its rating is calculated by summing the participants' answers and it varies from 8 to 32 units. The subscale's reliability has a Cronbach's alpha index of 0,85. 3) Maintaining Positive Outlook: The questions composing the subscale are 6. The internal validity was calculated with the 0,86 Cronbach's alpha coefficient and in the same way the subscale's rating is calculated which varies from 6 to 24 units. 4) Family Connectedness: It is composed of 6 questions, among which the four ones in which the scale was reversed for conceptual reasons are also included. The sum of the score of all the questions that compose it, shapes the subscale's rating which it can also vary from 6 as minimal value to 24 as maximum value. Its reliability, measured with the Cronbach's alpha coefficient, was found to be of 0,70. 5) Family Spirituality: The subscale is composed of 4 questions. From the sum of the answers' score its rating varies from 4 to 16 units and the measurement of its internal validity gave a Cronbach's alpha coefficient of 0,88. 6) Ability to Make Meaning of Adversity: It is formed by 3 questions, its rating is calculated by summing the answers of the respondent parents and it varies from 8 to 32 units. The subscale's reliability has a Cronbach's alpha index of 0,74 .

Taking into consideration the exception of 12 questions, it must be noted that the rating for the measurement of the total family resilience results from the horizontal sum of the 6 subscales and may vary from 66 to 264 units. Both for the total family resilience assessment scale and its entire individual subscales, higher scores indicate higher levels of family resilience. The reliability and internal validity in total for the tool used were calculated with the Cronbach's alpha coefficient and was found to be of 0,96. It is noted that the open-ended question was omitted.

Parenting Stress Index-Short Form: The parenting stress degree was measured by using the PSI-SF index (Abidin, 1995), which calculates the stress of the parents with children with autism spectrum disorders, which comes exclusively from their role as parents, without taking into consideration any external stressful factors, apart from the parent-child relation, as well as the child himself. The measurement tool consisted of 36 closed-type questions that were answered based on the 5-point Likert scale (1 to 5 = "I strongly disagree", "I disagree", "I am not sure", "I agree" and "I fully agree"). They were grouped together in three groups equal in number, that shaped the three index subscales as follows: 1) Parental Distress: It is made of questions 1-12 of the PSI-SF tool. The subscale rating is calculated by summing the answers and it varies from 12 to 60 units, reflecting the stress that is due to factors that concern the parents and which relate to the child's upbringing. The subscale's reliability has a Cronbach's alpha index of 0,85. 2) Parent-Child Dysfunctional Interaction: Questions 13 to 24 compose the second subscale of the Parenting Stress Index which represents the disappointment the parents feel regarding their interactions with their child. The sum of the score of all the questions that compose it, shapes its rating which may also vary from the minimum value of 12 units to the maximum value of 60 units. The subscale's reliability measured with the Cronbach's alpha coefficient was found to be of 0,68. 3) Difficulty of Child: It is formed by the twelve last questions in the questionnaire, 25 to 36 . Its rating is calculated by summing the parents' answers, it varies from 12 to 60 units and assesses their perception about the self-regulation of their child's behavior. The subscale's reliability has a Cronbach's alpha index of 0,78 .

The rating for the measurement of the total Parenting Stress results from the horizontal sum of the 3 subscales and varies from 66 to 264 units. Both for the scale and its subscales, high scores indicate high stress levels, whereas a low rating indicates low stress levels. According to the PSI-SF self-report index, the values between the $15^{\text {th }}$ and $80^{\text {th }}$ percentage point of distribution are considered to be normal stress levels, whereas for the individuals whose rating varies from values above the $90^{\text {th }}$ percentage point of distribution, it is regarded that they are in the clinical range of high stress levels. The reliability and internal validity in total for the tool used was calculated with the Cronbach's alpha coefficient and was found to be of 0,84 . 
The consistency check was performed via the alpha "coefficient" of Cronbach (Cronbach's a), with the use of which the reliability of the data collection tools and their individual parts is defined. Coefficient values higher than 0,6 are considered satisfactory and they ensure their cohesion and internal validity, functioning as elements of a unified group. For the description of the quantitative variables that participated in the statistical analysis, the mean values (Mean), the standard deviations (Standard Deviation $=\mathrm{SD}$ ), the minimal and maximum values (Min-Max) as well as the third and fourth order moments (Skewness and Kurtosis) of their distributions were used. In the case of the qualitative data, their description was made via the recording of their relevant absolute (n) and percent (\%) frequencies. The linear correlation check between the quantitative variables was conducted via the Pearson $r$ correlation coefficient. The $r$ correlation coefficient varies between -1 and 1 , whereas the higher it is in absolute value, the higher the correlation between the variables becomes. Even though there are no commonly accepted limits, index values, to an absolute value, lower than 0,3 indicate weak correlations, values between 0,3 and 0,5 indicate medium correlations, whereas values higher than 0,5 mark high and strong correlations. Positive values of the coefficient suggest a positive correlation, whereas negative values, a negative correlation. The statistical significance of the correlations is checked at significance levels $\alpha=1 \%$ and $\alpha=5 \%$. For the comparison of the quantitative variables and the drawing of the survey's main conclusions, the Independent Samples t-test and the Paired Samples t-test were used depending on the nature and kind of the variables under examination. Moreover, its generalization for variables with more than two levels, the one-way Analysis of Variance (ANOVA), was used. The further study on the differences in the factors' levels is carried out with the Tukey method for multiple comparisons. The check of the hypothesis on equality of the variances on the factors' levels is performed via the Levene's test, whereas the safeguarding of the basic conditions concerning regularity and independence of the method's errors was checked via the Kolmogorov-Smirnov test and the Runs test, respectively. The aforementioned hypothesis checks are performed at a significance level $\alpha=5 \%$. For the processing and statistical analysis of the data the IBM SPSS Statistics 20 data statistic analysis software package was used.

\section{Results}

Table 1 that follows shows the results of the statistical analysis on the investigation of the effects of the respondents' religious beliefs in the formation of the measured variables. The statistical Independent Samples $\mathrm{t}$-test for independent samples revealed, at significance level $a=b \%$, statistically significant differences at the levels of most survey scales and subscales, as understood from the values in the table.

Table 4. Comparison of mean values in the measurement scale and subscales regarding the respondents' religion

\begin{tabular}{|c|c|c|c|c|c|c|}
\hline Scales \& Subscales & Religion & Mean & SD & df & $\mathbf{t}$ & p-value \\
\hline \multirow{3}{*}{ SSI } & Christians & 42,62 & 4,503 & \multirow{3}{*}{622} & \multirow{3}{*}{10,883} & \multirow{3}{*}{$0,000 *$} \\
\hline & & & & & & \\
\hline & Muslims & 34,45 & 4,260 & & & \\
\hline \multirow{3}{*}{ FRAS totally } & Christians & 154,48 & 7,579 & \multirow{3}{*}{38,871} & \multirow{3}{*}{4,952} & \multirow{3}{*}{$0,000^{*}$} \\
\hline & & & & & & \\
\hline & Muslims & 144,55 & 12,209 & & & \\
\hline \multirow{3}{*}{ FCPS } & Christians & 78,96 & 4,310 & \multirow{3}{*}{38,821} & \multirow{3}{*}{4,570} & \multirow{3}{*}{$0,000 *$} \\
\hline & & & & & & \\
\hline & Muslims & 73,68 & 7,037 & & & \\
\hline \multirow{3}{*}{ USER } & Christians & 22,81 & 1,413 & \multirow{3}{*}{38,358} & \multirow{3}{*}{3,779} & \multirow{3}{*}{$0,001 *$} \\
\hline & & & & & & \\
\hline & Muslims & 21,16 & 2,666 & & & \\
\hline \multirow{3}{*}{ MPO } & Christians & 17,42 & 1,066 & \multirow{3}{*}{38,576} & \multirow{3}{*}{3,785} & \multirow{3}{*}{$0,001 *$} \\
\hline & & & & & & \\
\hline & Muslims & 16,26 & 1,870 & & & \\
\hline \multirow{3}{*}{$\mathrm{FC}$} & Christians & 14,96 & 0,721 & \multirow{3}{*}{39,544} & \multirow{3}{*}{1,221} & \multirow{3}{*}{0,229} \\
\hline & & & & & & \\
\hline & Muslims & 14,76 & 0,998 & & & \\
\hline FS & Christians & 11,70 & 1,467 & 40,519 & 2,520 & $0,016^{*}$ \\
\hline
\end{tabular}




\begin{tabular}{lcccccc}
\hline & Muslims & 10,97 & 1,732 & & & \\
AMMA & Christians & 8,63 & 0,886 & & & \\
& Muslims & 7,71 & 1,354 & 39,082 & 4,113 & $0,000^{*}$ \\
\multirow{2}{*}{ PSI-SF totally } & Christians & 115,09 & 15,481 & & & \\
& Muslims & 120,82 & 10,603 & 47,879 & $-3,120$ & $0,003^{*}$ \\
PD & Christians & 36,82 & 5,646 & & & \\
& Muslims & 39,84 & 4,433 & 622 & $-3,232$ & $0,001^{*}$ \\
P-CDI & Christians & 40,52 & 5,439 & & & \\
& Muslims & 41,63 & 4,043 & 622 & $-1,523$ & 0,216 \\
DC & Christians & 37,75 & 6,328 & & & \\
& Muslims & 39,34 & 4,795 & & & \\
\hline
\end{tabular}

Note. $*=\mathrm{p}<.05$.

\section{Memo}

SSI: $\quad$ Social Support Index

FRAS: $\quad$ Family Resilience Assessment Scale

FCPS: $\quad$ Family Communication and Problem Solving

USER: $\quad$ Utilizing Social and Economic Resources

MPO: $\quad$ Maintaining Positive Outlook

FC: $\quad$ Family Connectedness

FS: $\quad$ Family Spirituality

AMMA: $\quad$ Ability to Make Meaning of Adversity

PSI-SF: $\quad$ Parenting Stress Index - Short Form

PD: $\quad$ Parental Distress

P-CDI: $\quad$ Parent-Child Dysfunctional Interaction

DC: $\quad$ Difficulty of Child

As understood from Table 4, the differentiation in the average rating of the social support received by the parents with children with autism spectrum disorders is statistically significant $(t 622)=10,833, p=0,000)$, Christian parents showing higher average rating $M=42,62$ in comparison with Muslim parents for whom the average score is $M=34,45$. This conclusion also emerges for the total scale of family resilience FRAS $(t(\exists 8,871)=4,952, z=0,000)$ for which the average rating for Christians and Muslims is $M=154,46$ and $M=144,55$ respectively. The image for the index of total parenting stress PSI-SF is reverse, for which Muslim parents form higher levels of stress $M=120,82$ in comparison with the Christians for whom the respective average value of the index is formed to $M=115,09(t(4,7,789)=-3,120, p=0,003)$.

At the same significance level, the differences between the parents of a different religion emerged statistically significant for five out of six subscales of the family resilience. More specifically, regarding FCPS subscale $(t(38,871)=4,570, p=0,200)$, the average score of the Christians is higher $M=78,96$ against the Muslims' one $M=73,68$. For the USER component $(t(38,358)=3,779, p=0,001)$ the average rating of the Christians amounts to $M=22,81$, considerably higher than the value $M=21,16$ for the Muslims. The average ratings of the two populations for the MPO subscale $(t(38,576)=3,785, p=0,001)$ as well as for FS $(t(40,519):=2,520, p=0,016)$ are $M=17,42-16,26$ and $M=11,70-10,97$ respectively, Muslim parents forming lower levels of resilience in the subscales. Regarding AMMA subscale $(t(39,082)=4,113,2=0,000)$, the average scores for Christians and Muslims are formed to $M=8,63$ and $M=7,71$, respectively. Regarding the subscales of the parenting stress index, a statistically significant differentiation emerges only for the PD component $(t(622)=-3,232, p=0,001)$, the average rating of the subscale for the Muslim parents being 
$M=39,84$ and $M=36,82$ for the Christians. In Table 1 the person concerned can seek the results of the check for all the measured scales and subscales of the studied characteristics.

\section{Discussion}

From the analysis of the survey results it was found that the parent's religion affects the total family resilience, the Christian parents forming higher levels of resilience compared with the Muslims. Moreover, they appear more capable in family communication \& problem solving, they utilize better the social and economic resources, they maintain more positive outlook, they have a wider family spirituality and can easily make meaning of adversities in comparison with the Muslim parents. Furthermore, they receive bigger social support and form lower levels of total stress and parental distress.

There was deep concern on how these findings could be interpreted. Possibly the Christian parents pin their hopes on the divine intervention in order to address the problem of autism to a far smaller extent than the Muslims, or in terms of origin-Asian (Bashir, Khursid, \& Qadri, 2014) and African parents (Gona et al., 2016). This possibly means that they seek every possible scientific and social assistance in order to address with more efficiency the challenges of raising their autistic children, therefore they experience all those factors that enhance the resilience and cause a more positive outlook to the problem. On the contrary, as shown by the results of research in the non-western world, Asian and African parents pin, to a great extent, their hopes on divine intervention, besides they consider divine will to be the source of origin of autism. This may possibly mean that they perceive the treatment or management of the autistic child with non-scientific and non-social terms, a fact that possibly reduces their resilience over time, as they still remain helpless facing a problem that cannot be resolved. It could be supported that attributing the disease to the divine will may be connected with a kind of making meaning of adversity, however, the conclusion of our research on lesser social support of the Muslims, but also greater stress and distress, is in accordance with views that support that without social and scientific assistance the parents' resilience is significantly reduced.

Summing up the conclusions on religion, it should also be pointed out that intensified interest is found on the issue of autism in countries of the non-western world, as shown by the review of the research in the theoretical part of this paper. With the help of more research, the power of religion in the non-western world and the importance of the co-effect of factors, such as the low social and economic level of the parents of children with autism, could be gradually further assessed. Moreover, the non-Christian parents could be convinced to trust society and the healthcare professionals more than they usually do, without this meaning loss of their faith in the divine power, which they certainly have to dissociate as the sole factor of expected resilience. Finally, it could be said that the following conclusion of the theoretical part for the different handling of autism by parents of the non-western world is confirmed, who, in the case of our research, correspond to non-Christian parents living in the Greek territory. In the non-western world the feelings that the parents of autistic children experience are not affected by cultural differences, the way, however, in which they take care of their child is possibly differentiated. The awareness of the issues of autism, as well as the support from relatives and friends, is also important to these parents.

\section{Methodological Limitations}

The geographical distribution of the sample can be regarded as one basic limitation of the research. Despite the fact that as to its size, it is big enough and representative per district, it concerns only seven prefectures in the Greek territory. Consequently, generalizations of the conclusions that are drawn will have to be made with caution, even though it seems that they can be considered as particularly representative. An equally important limitation is that fact that the sample taken is exclusively from parents of a specific family structure. The families chosen are all two-parent families and the parents who participate in the survey have a specific family relation to the child. So, it cannot be assumed that the effects of the family structure and family relation have been adequately explored. Besides, the assessment that was made is based on the self-reports of the parents with a child with autism spectrum disorders, without other reports and information from other important persons of the parents' environment being detected, such as the rest of the families' members and health experts who possibly aid the parents. It must also be added that the survey is synchronic and interrelated, therefore it is not possible to discuss casual links between the factors under study. In addition, in this attempt no other possible parameters and co-morbidities linked to the levels of family resilience were assessed, such as depression, loneliness, the parents' interpersonal relations and social skills. All the aforementioned limitations must be taken into consideration during the study and interpretation of the present research findings. 


\section{Conclusions}

It has been shown that the parents of children with autism that are Christians, a fact that in Greece usually equals to their being of Greek origin, namely whites, are in a position of addressing their child's needs more efficiently, maybe because they attach more importance to the factor of the Divine compared to the parents of other religions, such as of the Muslim religion. It appears that the less connection of the origin and the management of the disease with God allows Greek Christians to understand the significance of scientific assistance to their problem, the confrontation of which they also perceive in more positive social terms than the Muslims. The increased, in recent years, interest in the syndrome of autism and its management in countries of the non-western world might instill the non-Christian parents with a more positive attitude towards the available scientific and social factors, so that the enhancement of their resilience according to the former ones give room to scientific methods for the treatment of the syndrome, while, according to the latter, lead to ascertainments that even personal health problems, such as the presence of an autistic child in the family environment, is not a problem that can become manageable without any wider social joint-action.

\section{References}

Abidin, R. R. (1995). Parenting Stress Index (3rd ed.). Odessa, FL: Psychological Assessment Resource.

Bashir, A., Khursid, A., \& Qadri, F. (2014). Awareness and Problems of Parents of Children with Autism Spectrum Disorders. International Journal of Interdisciplinary Research and Innovations, 2(2), 42-48.

Fischer, J., Corcoran, K., \& Fischer, J. (2007). Measures for clinical practice and research: A sourcebook. New York: Oxford University Press.

Gona, J. K., Newton, C. R., Rimba, K. K., Mapenzi, R., Kihara, M., Vijver, F. V., \& Abubakar, A. (2016). Challenges and coping strategies of parents of children with autism on the Kenyan coast. Rural and Remote Health, 16, 1-12.

Houser, R., \& Seligman, M. (1991). A comparison of stress and coping by fathers of adolescents with mental retardation and fathers of adolescents without mental retardation. Research in Developmental Disabilities, 12, 251-260. https://doi.org/10.1016/0891-4222(91)90011-G

Keller, D., \& Honig, A. S. (2004). Maternal and Paternal Stress in Families with School-Aged Children with $\begin{array}{lllll}\text { Disabilities. American Journal of } & \text { Orthopsychiatry, }\end{array}$ https://doi.org/10.1037/0002-9432.74.3.337

McCubbin, H. I., Patterson, J., \& Glynn, T. (1982). Social Support Index (SSI). In H. I. McCubbin, A. I. Thompson, \& M. A. McCubbin (Eds.), Family assessment: Resiliency, coping and adaptation-Inventories for research and practice (pp. 357-389). Madison, WI: University of Wisconsin System.

Tucker Sixbey, M. (2005). Development of the Family Resistance Assessment Scale to Identify Family Resilience Constructs. University of Florida. Retrieved December 3, 2014, from http://etd.fcla.edu/UF/UFE0012882/sixbey_m.pdf

Walsh, F. (2006). Strengthening family resilience (2nd ed.). New York: Guilford Press.

\section{Copyrights}

Copyright for this article is retained by the author(s), with first publication rights granted to the journal.

This is an open-access article distributed under the terms and conditions of the Creative Commons Attribution license (http://creativecommons.org/licenses/by/4.0/). 